\title{
Study on Spatiotemporal Characteristics of Tourism Demand for the Belt and Road Countries Based on Network Attention*
}

\author{
Bo Gong \\ School of Economics and Management \\ Beijing Jiaotong University \\ Beijing, China
}

\begin{abstract}
Network attention rate is an intuitive measurement of demand of tourists on the Internet. Based on the methods of Baidu index, this paper uses some statistical analysis indicators, which are Coefficient of Variation and Gini Coefficient, to analyze spatiotemporal characteristics of network attention of tourism of the Belt and Road (B\&R) countries, and establishes a regression equation to discuss the main influencing factors which cause differences of spatial characteristics among provinces in China. It turns out that, the network attention of tourism of all $B \& R$ countries of Chinese tourists shows vibration like "mountain" shape in a year, which is mainly affected by the length of holidays; the curves of the network attention of single country can be divided into three types: single-peak, double-peak and multi-peak, the network attention of single-peak countries vibrates a lot in a year while which of multi-peak countries vibrates a little. In the aspect of spatial characteristics, developed provinces and provinces with large population have relatively high network attention rate of tourism of all $B \& R$ countries, but the differences of network attention among provinces in China are relatively small; the crowd who pay attention to the traditional outbound tourism destinations is evenly distributed while the crowd who pay attention to the unpopular outbound tourism destinations is mainly distributed in developed provinces; population and disposable income of urban households are the key factors that caused the differences of network attention among provinces in China.
\end{abstract}

Keywords-the Belt and Road $(B \& R)$; tourism demand; network attention; baidu index; spatiotemporal characteristics

\section{INTRODUCTION}

With the popularity of the Internet, more and more tourists are beginning to search for information of tourism destination through the Internet. As of December 2016, the number of Internet users in China reached 731 million, and the Internet penetration rate reached $53.2 \%$. The Internet has become an important approach for tourists to obtain tourism information, and provides a basis for tourists' behavior. Tourists will leave corresponding search traces when they search for information of tourism destination online. These traces will be statistically collected to form network attention.

*Supported by "the Fundamental Research Funds for the Central Universities" (No.2017JBZ005)
Therefore, network attention of tourism is the intuitive inflection of tourism demand online. Baidu index, the data sharing platform provided by Baidu, which is the largest Chinese search engine in the world, has become an important tool for research of network attention, which is based on the search behavior of its large number of users. With the use of Baidu index, S.Li, R.Qiu and L.Chen analyzed the temporal distribution characteristic of network attention of tourist attractions [1]. L.Ma, G.Sun, Y.Huang and R.Zhou constructed a spatiotemporal correlation model of domestic tourists and tourists' network attention [2]. W.Lin, Y.Zou and X.Zheng used the method of Theil index to analyze the regional differences of network attention of domestic tourism safety [3]. X.Li and H.Qu used seasonal intensity index and regression analysis to discuss the spatiotemporal characteristics and its influencing factors of network attention of domestic cruise tourism[4]. X.He, Y.Liu and F.Wu used statistical indicators such as coefficient of variation and Gini coefficient to research spatiotemporal characteristics of network attention of hot spring tourism in China [5].

In 2013, Chairman Xi Jinping put forward the significant proposition of jointly building the Silk Road Economic Belt and the 21st Century Maritime Silk Road, which can be abbreviated as the Belt and Road (B\&R). Promote the construction of the Silk Road Economic Belt and the vision and action of the maritime Silk Road in twenty-first Century, which was published by the government in 2015, clearly pointed that it was necessary to strengthen tourism cooperation and expand the scale of tourism, which meant that the related research on the tourism of the B\&R countries had become increasingly important. Z.Li and B.Xiao used PCA-PDA combination model to measure the development efficiency of culturaland tourism industry in B\&R Provinces[6]. Y.Zou used the method of social network analysis to discuss the spatial network structure of tourism economic connection in the major node B\&R cities in China[7]. J.Yin, Y.Liu, D.Yang and X.Zheng used relevant spatial measurement model to examine the spatial effects of tourism liberalization in European $\mathrm{B} \& \mathrm{R}$ countries and discussed its driving factors[8]. 
Most of the research on spatiotemporal characteristics with the use of network attention focused on domestic tourism and there are only a few papers focusing on tourism of the B\&R countries. Therefore, based on the search data of Baidu index, this paper takes the tourism of the $B \& R$ countries as the object and collects network attention data of tourism of the B\&R countries from January to December in 2017.After that, this paper compares and analyzes the differences of the data from spatial and temporal perspective and reveals the spatiotemporal characteristics and differences of the current tourism demand for the B\&R countries, which aimed at providing references for enriching the research on tourism demand and developing relevant outbound tourism market.

\section{DATA SOURCES AND RESEARCH METHODS}

\section{A. Data Sources}

This paper uses "country name + tourism" of the B\&R countries as the keywords to search for their network attention. There are 30 countries' keywords of tourism that are not included in 65 countries along the B\&R route except China, because their search data is not enough or the tourism industry of them are underdeveloped so that the relevant data cannot be viewed. Therefore, this paper takes the remaining 35 countries as the searching targets. The daily averages of the network attention of the 35 countries from the whole country in each month in 2017 and the daily averages of network attention of the 35 countries from each province in China in 2017 are collected respectively.

In addition, this paper also needs the population, regional GDP, regional per capita disposable income of urban households, and internet penetration rate of each province in China in 2017. The first three indicators come from the 2017 China Statistical Yearbook published by the National Bureau of Statistics, and the last one comes from the 39th China Statistical Report on Internet Development published by China Internet Network Information Center.

\section{B. Research Methods}

With the use of statistical methods such as coefficient of variation and Gini coefficient, this paper analyzes the spatiotemporal characteristics of network attention of tourism of the $35 \mathrm{~B} \& \mathrm{R}$ countries. The analysis of temporal dimension takes month as the unit to discuss Chinese tourists' temporal differences of network attention of tourism of each country; the analysis of spatial dimension takes province as the unit to discuss Chinese tourists' spatial differences of network attention of tourism of each country.

1) Coefficient of variation: This paper uses coefficient of variation to measure the monthly vibration of the network attention of tourism of the B\&R countries. The coefficient of variation, which is used to measure the extent of variation in a set of data, is the ratio of the standard deviation of a set of data to its mean value. The formula is:

$$
\mathrm{CV}=\frac{1}{y} \sqrt{\sum_{i=1}^{n}\left(Y_{i}-\bar{y}\right)^{2} / n}
$$

In this formula, CV stands for the coefficient of variation, $\mathrm{n}$ stands for the number of months in a year. This formula sets month as $i$ and yi stands for the network attention of the i month, $\bar{y}$ stands for the mean value of yi. The bigger the coefficient of variation is, the more different monthly vibration of network attention of tourism of the $B \& R$ countries is. In other words, the Internet users who pay attention to the tourism of $\mathrm{B} \& \mathrm{R}$ countries are concentrated in one or some months. On the contrary, the smaller the coefficient of variation is, the less different monthly vibration of network attention of tourism of the B\&R countries is. In other words, the Internet users who pay attention to the tourism of $B \& R$ countries are relatively evenly distributed in each month in a year.

2) Gini coefficient: This paper uses Gini coefficient to measure inter-provincial differences of the network attention of tourism of the B\&R countries. As an index to measure the extent of income disparity, Gini coefficient has become a common method to research regional economic development disparities. The formula is:

$$
\mathrm{G}=\frac{1}{N W_{N}} \sum_{i=2}^{W} \sum_{j=1}^{i-1}\left(Q_{i}-Q_{j}\right)
$$

In this formula, $\mathrm{G}$ stands for the Gini coefficient, $\mathrm{N}$ stands for the number of provinces in China, WN stands for the total network attention of tourism of the B\&R countries, Qi stands for the Baidu index of the i province after ranking Baidu indexes of all provinces from low to high and $\mathrm{Qj}$ stands for the Baidu index of the province which is behind the $\mathrm{i}$ province in the rank. The bigger the Gini coefficient is, the greater the inter-provincial difference of network attention is. In other words, the Internet users who pay attention to the tourism of $\mathrm{B} \& \mathrm{R}$ countries are concentrated in one or some provinces. Rather, the smaller the Gini coefficient is, the smaller the inter-provincial difference of network attention is. In other words, the Internet users who pay attention to the tourism of B\&R countries are relatively evenly distributed in each province in China.

\section{TEMPORAL CHARACTERISTICS}

\section{A. Temporal Characteristics of the Network Attention of Tourism of All B\&R Countries}

This paper sums up monthly network attention of tourism of all 35 B\&R countries and makes a statistical figure (Figure 1) to analyze the temporal characteristics of Chinese Internet users' network attention of tourism of the B\&R countries. It turns out that, the network attention of tourism of all B\&R countries shows vibration like "mountain" shape in a year. It is so cold in January that tourists are unwilling to tour, which means that the tourism demand is weak. There is a small peak in February because of the Spring Festival, which is a relatively long holiday. With the improvement of the income level and increasingly facilitation of outbound 
tourism, more and more tourists choose to spend the Spring Festival abroad. Though there are Qingming Festival and May Day from March to June, the length of holiday is too short for outbound tourism so that tourists are unwilling to tour. Despite the hot weather in August, tourism demand increases significantly, which forms the second peak in a year, because of the summer vacation of schools and annual leave of companies. In addition, the network attention shows an upward trend before August. From September to November, the network attention falls back due to the start of new semester and the cold weather. December is near New Year's Day and Spring Festival, tourism demand increases again so that the network shows an upward trend.

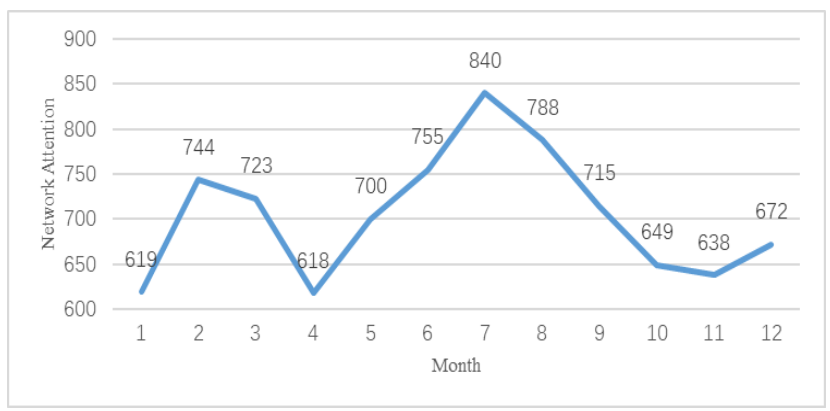

Fig. 1. Daily average of network attention of $B \& R$ countries of each Month in 2017.

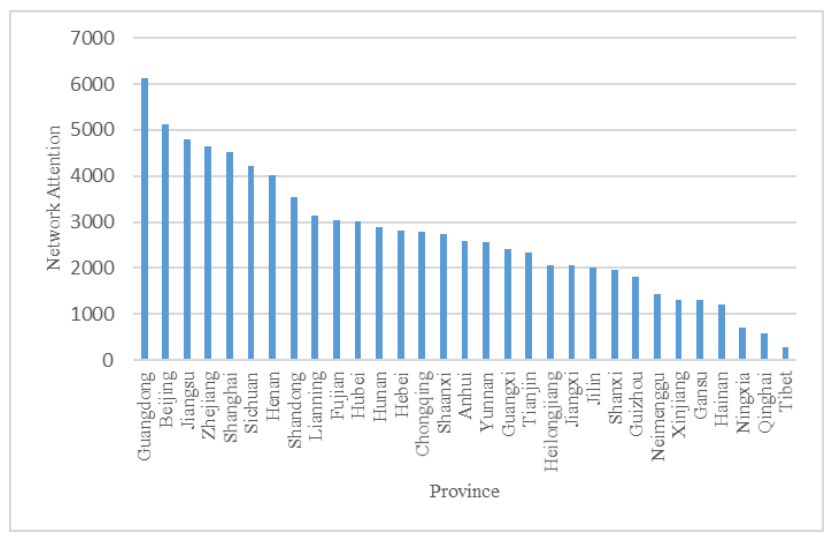

Fig. 2. Daily average of network attention of $B \& R$ countries of each Month in 2017.

The coefficient of variation of network attention of tourism of the $35 \mathrm{~B} \& \mathrm{R}$ countries is calculated by (1) and the result is 0.094, which means that, although there is certain monthly vibration of network attention in a year, it is relatively small.

\section{B. Temporal Characteristics of the Network Attention of Tourism of Single B\&R Country}

This paper calculates the Chinese Internet users' monthly network attention of tourism of the $35 \mathrm{~B} \& \mathrm{R}$ countries in 2017. The 35 countries can be divided into three types: single-peak type, double-peak type and multi-peak type according to the results (Table 1). For example, 5 countries such as Hungary and Czech are single-peak type countries; 12 countries are such as Cambodia and Kazakhstan are double-peak type countries; 18 countries such as Malaysia and the United Arab Emirates are multi-peak type countries.

The coefficients of variation $(\mathrm{CV})$ of network attention of tourism of the $35 \mathrm{~B} \& \mathrm{R}$ countries are calculated by (1), and the results are shown in "Table I". The coefficients of variation of 8 countries such as Malaysia and the United Arab Emirates are below 0.1, which means that there is little difference in monthly vibration of network attention; The coefficients of variation of 15 countries such as Egypt and Sri Lanka are between 0.1 and 0.2 , which means that monthly vibration of network attention varies ordinarily. The coefficients of variation of 12 countries such as Greece and Slovakia are above 0.2 , which means that monthly vibration of network attention varies greatly.

Considering the type of curves and coefficients of variation synthetically, it can be found that single-peak type countries' coefficients of variation are generally high and their monthly vibration of network attention varies greatly, which means that there are clear slack and peak seasons. Double-peak countries' coefficients of variation are ordinary, while multi-peak countries' coefficients of variation are generally small and there is little difference in their monthly vibration of network attention, which means that their reception of tourists is relatively stable.

\section{SPATIAL CHARACTERISTICS}

\section{A. Spatial Characteristics of the Network Attention of Tourism of All B\&R Countries}

With the use of Baidu index's function of region selection, this paper collects each province's network attention of tourism of the $35 \mathrm{~B} \& \mathrm{R}$ countries. According to the results shown in Figure 2, the provinces ranked in the top ten are Guangdong, Beijing, Jiangsu, Zhejiang, Shanghai, Sichuan, Henan, Shandong, Liaoning and Fujian, which are mainly developed provinces along the southeast coast and provinces with large population.

The Gini coefficient of the total network attention of tourism of the $35 \mathrm{~B} \& \mathrm{R}$ countries are calculated by (2) and the result is 0.337 , which means that the differences of network attention among provinces in China are relatively small. It also indicates that, with the economic development of China, the increase of disposable income per capita and the increasingly facilitation of tourism of the B\&R countries after proposing the $\mathrm{B} \& \mathrm{R}$, tourists from each province are beginning to pay attention to outbound tourism in the context of the mass tourism era. Outbound tourism is no longer the exclusive products of high-income groups or developed provinces. 
TABLE I. CURVE TYPE AND COEFFICIENT OF VARIATION OF NETWORK ATTENTION OF B\&R COUNTRIES IN 2017

\begin{tabular}{|l|l|l|l|l|l|}
\hline Type & Country & \multicolumn{1}{c|}{ CV } & \multicolumn{1}{|c|}{ Type } & \multicolumn{1}{|c|}{ Country } & \multicolumn{1}{c|}{ CV } \\
\hline single & Maldives & 0.29 & multiple & Malaysia & 0.041 \\
\hline single & Czech & 0.308 & multiple & UAE & 0.064 \\
\hline single & Turkey & 0.326 & multiple & Poland & 0.078 \\
\hline single & Russia & 0.368 & multiple & Jordan & 0.08 \\
\hline single & Kyrgyzstan & 0.477 & multiple & Nepal & 0.082 \\
\hline double & Cambodia & 0.093 & multiple & Hungary & 0.083 \\
\hline double & Kazakhstan & 0.129 & multiple & Philippines & 0.09 \\
\hline double & Belarus & 0.144 & multiple & Egypt & 0.109 \\
\hline double & Singapore & 0.154 & multiple & Sri Lanka & 0.113 \\
\hline double & Indonesia & 0.164 & multiple & Syria & 0.118 \\
\hline double & Vietnam & 0.195 & multiple & Cyprus & 0.124 \\
\hline double & Greece & 0.217 & multiple & Burma & 0.133 \\
\hline double & Croatia & 0.233 & multiple & Israel & 0.133 \\
\hline double & Latvia & 0.24 & multiple & Brunei & 0.141 \\
\hline double & Bhutan & 0.25 & multiple & Thailand & 0.15 \\
\hline double & India & 0.303 & multiple & Laos & 0.15 \\
\hline double & Pakistan & 0.379 & multiple & Slovenia & 0.198 \\
\hline & & & multiple & Slovakia & 0.223 \\
\hline
\end{tabular}

TABLE II. GINI COEFFICIENT OF NETWORK ATTENTION OF B\&R COUNTRIES IN 2017

\begin{tabular}{|l|c|l|l|l|l|}
\hline Country & GC & \multicolumn{1}{|c|}{ Country } & GC & \multicolumn{1}{c|}{ Country } & GC \\
\hline Nepal & 0.267 & Thailand & 0.341 & Belarus & 0.566 \\
\hline Russia & 0.278 & Philippines & 0.344 & Poland & 0.583 \\
\hline Vietnam & 0.282 & India & 0.35 & Syria & 0.597 \\
\hline Egypt & 0.292 & Laos & 0.357 & Croatia & 0.6 \\
\hline Turkey & 0.293 & Brunei & 0.381 & EAU & 0.615 \\
\hline Pakistan & 0.3 & Sri Lanka & 0.381 & Jordan & 0.626 \\
\hline Malaysia & 0.301 & Bhutan & 0.405 & Slovenia & 0.649 \\
\hline Singapore & 0.309 & Czech & 0.415 & Hungary & 0.679 \\
\hline Maldives & 0.321 & Indonesia & 0.452 & Cyprus & 0.723 \\
\hline Cambodia & 0.323 & Latvia & 0.487 & Slovakia & 0.724 \\
\hline Israel & 0.326 & Burma & 0.532 & Kyrgyzstan & 0.766 \\
\hline Greece & 0.331 & Kazakhstan & 0.556 & & \\
\hline
\end{tabular}

\section{B. Spatial Characteristics of the Network Attention of} Tourism of Single B\&R Country

Each province's network attention of tourism of the 35 $\mathrm{B} \& \mathrm{R}$ countries is collected and the Gini coefficient (GC) of them are calculated by (2). According to the results showed in "Table II", the Gini coefficients of 22 countries such as Nepal and Russia are below 0.5, indicating that the differences of network attention among provinces in China are relatively small. Some of these countries are located in Southeast Asia or border with China, some of them are Chinese tourists' traditional outbound tourism destinations because of their developed tourism industry. Some countries such as Nepal and Bhutan are also favored by Chinese tourists because of their low level of consumption. Due to the above reasons, tourists who want to visit these countries are evenly distributed in each province in China. The Gini coefficients of 13 countries such as Kazakhstan and Belarus are above 0.41 , indicating that the differences of network attention among provinces in China are relatively big. Most of these countries are not Chinese tourists' traditional outbound tourism destinations because they are located in Europe and are geographically distant from China. There are not abundant tourism resources in some of them such as Kyrgyzstan and Syria. Therefore, tourists who want to visit these countries are mostly distributed in developed provinces, which lead to the situation that the differences of network attention among provinces in China are relatively big.

\section{Analysis of Influencing Factors of Spatial Difference}

The level of regional economic development and disposable income of urban households are important factors influencing tourists' choice of destination. Baidu Index is based on the search behavior of Internet users. Therefore, the regional population and Internet penetration rate have a close relationship with Baidu index. This paper selects four indicators, which are population, regional GDP (RGDP), disposable income per capita of urban households (DIPCUH) and the internet penetration rate (IPR), of all provinces in China in 2017 to discuss the influencing factors of the spatial difference of network attention (NA) of tourism of the B\&R countries. Because the mainstream web search engine in Hong Kong, Macau and Taiwan is not Baidu, leading to their relatively low Baidu index which cannot reflect the real tourism demand, these three regions are excluded. The data of the remaining 31 provinces are showed in "Table III".

TABLE III. NETWORK ATTENTION OF B\&R COUNTRIES AND RELATED INFLUENCING FACTORS OF 31 PROVINCES IN 2017

\begin{tabular}{|l|l|l|l|l|l|}
\hline \multicolumn{1}{|c|}{ Province } & NA & Population & \multicolumn{1}{|c|}{ RGDP } & DIPCUH & IPR \\
\hline China & 84940 & 138271 & 744127.2 & 33616.2 & $53.20 \%$ \\
\hline Beijing & 5118 & 2173 & 25669.13 & 57275.3 & $77.80 \%$ \\
\hline Tianjin & 2348 & 1562 & 17885.39 & 37109.6 & $64.60 \%$ \\
\hline Hebei & 2820 & 7470 & 32070.45 & 28249.4 & $53.30 \%$ \\
\hline Shanxi & 1964 & 3682 & 13050.41 & 27352.3 & $55.50 \%$ \\
\hline Neimenggu & 1443 & 2520 & 18128.1 & 32974.9 & $52.20 \%$ \\
\hline Liaoning & 3146 & 4378 & 22246.9 & 32876.1 & $62.60 \%$ \\
\hline Jilin & 1997 & 2733 & 14776.8 & 26530.4 & $50.90 \%$ \\
\hline Heilongjiang & 2068 & 3799 & 15386.09 & 25736.4 & $48.10 \%$ \\
\hline Shanghai & 4533 & 2420 & 28178.65 & 57691.7 & $74.10 \%$ \\
\hline Jiangsu & 4785 & 7999 & 77388.28 & 40151.6 & $56.60 \%$ \\
\hline Zhejiang & 4646 & 5590 & 47251.36 & 47237.2 & $65.60 \%$ \\
\hline Anhui & 2583 & 6196 & 24407.62 & 29156 & $44.30 \%$ \\
\hline Fujian & 3040 & 3874 & 28810.58 & 36014.3 & $69.70 \%$ \\
\hline Jiangxi & 2053 & 4592 & 18499 & 28673.3 & $44.60 \%$ \\
\hline Shandong & 3548 & 9947 & 68024.49 & 34012.1 & $52.90 \%$ \\
\hline Henan & 4013 & 9532 & 40471.79 & 27232.9 & $43.40 \%$ \\
\hline Hubei & 3024 & 5885 & 32665.38 & 29385.8 & $51.40 \%$ \\
\hline Hunan & 2892 & 6822 & 31551.37 & 31283.9 & $44.30 \%$ \\
\hline Guangdong & 6139 & 10999 & 80854.91 & 37684.3 & $74.00 \%$ \\
\hline Guangxi & 2421 & 4838 & 18317.64 & 28324.4 & $46.10 \%$ \\
\hline Hainan & 1193 & 917 & 4053.2 & 28453.5 & $51.60 \%$ \\
\hline Chongqing & 2781 & 3048 & 17740.59 & 29610 & $51.60 \%$ \\
\hline Sichuan & 4230 & 8262 & 32934.54 & 28335.3 & $43.60 \%$ \\
\hline Guizhou & 1811 & 3555 & 11776.73 & 26742.6 & $43.20 \%$ \\
\hline Yunnan & 2551 & 4771 & 14788.42 & 28610.6 & $39.90 \%$ \\
\hline Tibet & 275 & 331 & 1151.41 & 27802.4 & $46.10 \%$ \\
\hline Shaanxi & 2749 & 3813 & 19399.59 & 28440.1 & $52.40 \%$ \\
\hline Gansu & 1312 & 2610 & 7200.37 & 25693.5 & $42.40 \%$ \\
\hline Qinghai & 576 & 593 & 2572.49 & 26757.4 & $54.50 \%$ \\
\hline Ningxia & 715 & 675 & 3168.59 & 27153 & $50.70 \%$ \\
\hline Xinjiang & 1316 & 2398 & 9649.7 & 28463.4 & $54.90 \%$ \\
\hline & This pap & & & & \\
\hline
\end{tabular}

This paper takes each province's network attention as the dependent variable, and the above four indicators as independent variables. The result, which is concluded from multiple linear regression analysis by SPSS 22.0, is shown in "Fig. 3". The VIF of each variable is below 10, indicating that the collinearity among the variables is not significant. The values of Significance of Internet penetration rate and 
regional GDP are both above 0.05 , indicating that the impact of these two indicators on the degree of network attention is not significant. Therefore, this paper excludes these two indicators are excluded and uses the remaining two indicators, which are population and disposable income per capita of urban households, to make the multiple linear regression analysis again. The result is shown in "Fig. 4". The coefficient of determination (R2) of the equation model is 0.948. After correction, $\mathrm{R} 2=0.892, \mathrm{~F}=125.283$, indicating that the regression model is fitting well and the two indicators can explain $89.2 \%$ of the dependent variable. The equation is:

$$
\mathrm{Y}=0.679 \mathrm{X}_{1}+0.646 \mathrm{X}_{2}
$$

In this equation, $\mathrm{Y}$ stands for each province's tourists' network attention of tourism of the B\&R countries, X1 stands for population of each province, X2 stands for disposable income per capita of urban households of each province. Equation (3) turns out that, population and disposable income per capita of urban households both affect network attention a lot. If the number of population of a single province increases (or reduces) 10000, the number of this province's tourists' network attention of tourism of the $\mathrm{B} \& \mathrm{R}$ countries increases (or reduces) 0.679 in a single day. If the number of disposable income per capita of urban households of a single province increases (or reduces) 1 , the number of this province's tourists' network attention of tourism of the B\&R countries increase (or reduces) 0.646 in a single day. $\alpha+\beta=\chi$. (1) (1)

Coefficients $^{a}$

\begin{tabular}{|c|c|c|c|c|c|c|c|c|}
\hline \multirow[b]{2}{*}{ Mod } & & \multicolumn{2}{|c|}{ Unstandardized Coefficients } & \multirow{2}{*}{$\begin{array}{c}\begin{array}{c}\text { Standardized } \\
\text { Coefficients }\end{array} \\
\text { Beta }\end{array}$} & \multirow[b]{2}{*}{$t$} & \multirow[b]{2}{*}{ Sig. } & \multicolumn{2}{|c|}{ Collinearity Statistics } \\
\hline & & $B$ & Std. Error & & & & Tolerance & VIF \\
\hline \multirow[t]{5}{*}{1} & (Constant) & -3323.774 & 685.757 & & -4.847 & .000 & & \\
\hline & Population & .411 & .078 & .831 & 5.293 & .000 & .137 & 7.285 \\
\hline & RGDP & -.012 & .012 & -.164 & -.965 & .344 & .116 & 8.586 \\
\hline & DIPCUH & .092 & .018 & .543 & 5.254 & .000 & .317 & 3.153 \\
\hline & IPR & 2815.326 & 1475.268 & .206 & 1.908 & .067 & .292 & 3.427 \\
\hline
\end{tabular}

a. Dependent Variable: NA

Fig. 3. Regression coefficient and test results.

Coefficients $^{a}$

\begin{tabular}{|c|c|c|c|c|c|c|c|c|}
\hline \multirow{2}{*}{\multicolumn{2}{|c|}{ Model }} & \multicolumn{2}{|c|}{ Unstandardized Coefficients } & \multirow{2}{*}{$\begin{array}{c}\begin{array}{c}\text { Standardized } \\
\text { Coefficients }\end{array} \\
\text { Beta }\end{array}$} & \multirow[b]{2}{*}{$t$} & \multirow[b]{2}{*}{ Sig. } & \multicolumn{2}{|c|}{ Collinearity Statistics } \\
\hline & & $B$ & Std. Error & & & & Tolerance & VIF \\
\hline \multirow[t]{3}{*}{1} & (Constant) & -2331.508 & 361.495 & & -6.450 & .000 & & \\
\hline & Population & .336 & .030 & .679 & 11.327 & .000 & .999 & 1.001 \\
\hline & DIPCUH & .110 & .010 & .646 & 10.773 & .000 & .999 & 1.001 \\
\hline
\end{tabular}

a. Dependent Variable: NA

Fig. 4. Corrected regression coefficient and test results.

The regional GDP and Internet penetration rate have been seen as factors influencing the network attention of tourism in previous research. In this paper, because region's network attention of outbound tourism has a strong correlation with disposable income of urban households, the higher disposable income the urban households have, the higher the level of regional economic development is, and the higher the regional GDP and Internet penetration rate are. Therefore, the impact of these two indicators on network attention is included by disposable income per capita of urban households.

\section{CONCLUSION}

\section{A. Conclusion}

With the use of Baidu index, this paper analyzes the spatiotemporal characteristics of the network attention of tourism of $35 \mathrm{~B} \& \mathrm{R}$ countries by calculating and comparing their coefficients of variation and Gini coefficients. Also, the regression equation is established by taking the relevant influencing factors of each province as independent variables.

1) Temporal characteristics: Chinese tourists' network attention of tourism of the $35 \mathrm{~B} \& \mathrm{R}$ countries shows vibration like "mountain" shape, which is mainly affected by the length of holidays. Summer holiday period is the highest peak of the network attention in a year, and Spring Festival period is the second. The curves of the network 
attention of single country can be divided into three types: single-peak, double-peak and multi-peak. Single-peak countries' coefficients of variation are generally high and there are clear slack and peak seasons. Double-peak countries' coefficients of variation are ordinary while multipeak countries' coefficients of variation are generally small and their reception of tourists is relatively stable.

2) Spatial characteristics: Developed provinces along the southeast coast and provinces with large population have relatively high network attention rate of tourism of all B\&R countries, but the differences of network attention among provinces in China are relatively small. Outbound tourism is no longer the exclusive products of high-income groups or developed regions. The crowd who pay attention to the traditional outbound tourism destinations, which are close to China or have low level of consumption, is evenly distributed in each province. On the contrary, the crowd who pay attention to unpopular outbound tourism destinations, which are far from China or have high-quality tourism resources, is mainly distributed in developed provinces leading to the situation that the differences of network attention among provinces are relatively big. In addition, population and disposable income of urban households are the key factors that caused the differences of network attention among provinces in China.

\section{B. Research Prospect}

Based on the network attention, this paper reveals the spatiotemporal distribution characteristics and influencing factors of Chinese tourists' demand for tourism of the B\&R countries and enriches the research on tourism demand and tourism of B\&R countries. However, it still has some deficiencies. First of all, part of the network attention comes from non-tourists' search behavior, so the network attention cannot accurately reflect tourism demand. Second, some tourists may choose other websites to search for information and the keywords searched by Internet users may also be different, which leads to some deviation of the results. Finally, only indicators which are easy to quantify are used to construct the model, which causes that the accuracy and explanatory power of the model are slightly insufficient. In summary, the above deficiencies will be gradually improved in the future research.

\section{REFERENCES}

[1] S.Li, R.Qiu and L.Chen, "Cyberspace Attention of Tourist Attractions Based on Baidu Index: Temporal Distribution and Precursor Effect," Geography and Geo-Information Science, 2008, vol. 6, pp. 102-107.

[2] L.Ma, G.Sun, Y.Huang and R.Zhou, "A Correlative Analysis on the Relationship between Domestic Tourists and Network Attention," Economic Geography, 2011, vol. 4, pp. 680-685.

[3] W.Lin, Y.Zou and X.Zheng, "Study on the Regional Disparity in the Network Attention of China Tourism Security: Based on the Baidu Index of Tourism Security in 31 Provinces," Human Geography, 2014, vol. 6, pp. 154-160.

[4] X.Li and H.Qu, "Spatial-temporal Characteristic and Influential Factors of Network Attention to Cruise Tourism: Based on Baidu Index," Statistics\& Information Forum, 2016, vol. 4, pp. 101-106.
[5] X.He, Y.Liu and F.Wu, "Analysis on Temporal and Spatial Characteristics of Network Attention of Hot Spring Tourism Based on Baidu Index," Areal Research and Development, 2017, vol.1, pp. 103-108+124.

[6] Z.Li and B.Xiao, "On the Efficiency of Cultural Tourist Industry in the Provinces along 'One Belt and One Road'," Journal of Guangxi Teachers Education University (Philosophy and Social Sciences Edition), 2016, vol.2, pp. 42-47+87.

[7] Y.Zou, "Research on the Spatial Structure and Space Layout of Tourism Economic Relationship between Node Cities of China on the 'One Belt and One Road'," Business Management Journal, 2017, vol.5, pp. 22-35.

[8] J.Yin, Y.Liu, D.Yang and X.Zheng, "Study on Tourism Openness of European Countries along the 'B\&R'," Economic Geography, 2017, vol.6, pp. 190-197. 